\title{
Analysis and optimisation of temperature distribution in busbars and its contacts
}

\author{
Kolimas Łukasz
}

\begin{abstract}
This work presents an analysis of heating up process for busbars and contacts, along with means to optimize temperature distribution in constructions of this type (through an appropriate selection of their sizes and shape). Formulated are the final conclusions from the research carried out with the help of ANSYS software.
\end{abstract}

Keywords - busbars contacts temperature distribution

\section{INTRODUCTION}

The development of modern electroenergetics is related to the increase in voltage and current rated values (as well as shortcircuit current values) that power electrical equipment. As a result, current paths and contact systems must have higher continuous and short-circuit ampacity. The occurrence of contact resistance phenomenon causes contacts to be exposed to the largest loads. There are many restrictions imposed upon busbars and a lot of requirements that need to be met. Conductive material should display relevant characteristics when it comes to its purpose and consequent use. These include: low resistivity, high thermal resistance, low resistivity of coating layer, high resistance to corrosion, high mechanical strength, low production costs, low thermal expansion and high resistance to wear. Out of all conductive materials, copper is the one that meets most of the requirements [1]. Busbars of various shapes and cross-sections are manufactured, with the rectangular cross-section being the most common. Such shape is related to the optimal electromagnetic field distribution and to the removal of effects responsible for the loss of power in the flow path. The convection surface makes for yet another factor that favours utilisation of this type of cross-section.

Given the above, this article presents an analysis of temperature distribution in a rigid heavy-current busway shown as two busbars with rectangular cross-section that form contacts system. The research was carried out for constructions of diverse dimensions and shapes. The analysis may help better understand physical phenomenons occurring during the utilization of heavy-current busways that are being used to transmit large amounts of power. In accordance with Joule's first law, an integral part of the electric current flow is heat generation, which value is proportional to the square of the current multiplied by the electrical resistance. Therefore this article is specifically focused on the exploration of temperature distribution, which is influenced by factors such as skin effect, contact resistance, and heat exchange with the environment. The research was carried out using ANSYS software, which allows for the modelling and analysing of systems by utilizing the finite element method.

\section{TEORETICAL ISSUES}

Using modern software in the research has one notable advantage, in that it allows an opportunity to conduct many tests without exposing the equipment to possible damage. ANSYS is a simulation software that utilizes the finite element method; a method commonly used in engineering calculations. The ability to construct a model of particular geometry and to define corresponding parameters along with environmental conditions enables one to meticulously recreate the actual construction. The finite element SOLID226 was chosen when creating the model. All parameters specific for copper in SI units were selected accordingly. A special layer was created between the busbars (representing copper oxide present in that spot) $[2,3]$, with relevant values determined for it. In order to receive temperature distribution, instantaneous analysis at environment temperature of $40^{\circ} \mathrm{C}$ was carried out. Therefore the results do not illustrate specific values to which busbars heat up; they merely show the temperature in a given moment - the same one for each of the analysed constructions. Furthermore, the nature of the effects taking place due to construction changes is manifested within the results, which allows to determine the differences between particular models. The busbars were being modified in such a way as to receive the lowest possible temperature at its best (uniform) distribution. For that purpose, specific construction sizes and its shape were being altered. The following figure illustrates the effect for proportion of the length of contact overlap to the thickness of busbar at contact resistance value. 


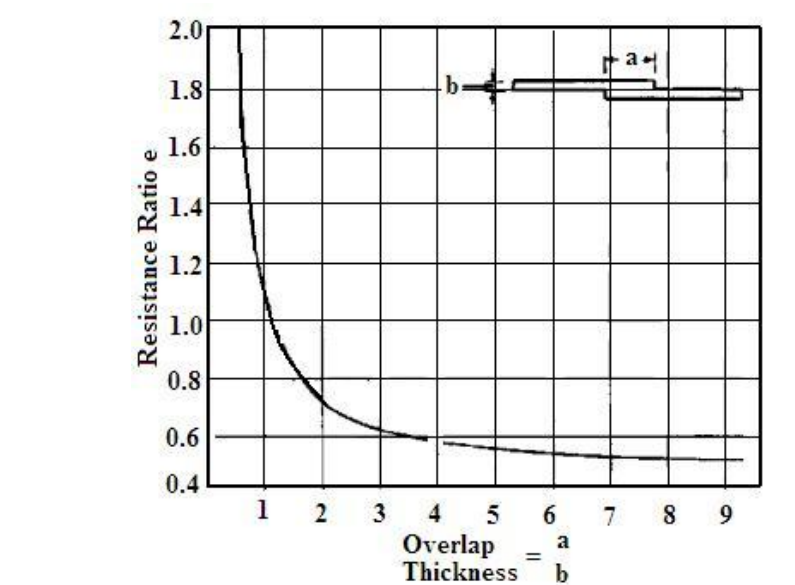

Fig.1.The effect for proportion of the length of contact overlap to the thickness [4].

Contact resistance of busbars whose edges are cut at 45 degrees may be even $15 \%$ lower than that of busbars without such cuts [5]. This shape additionally provides a larger surface of heat transfer.

\section{BASIC CONSTRUCTION}

This geometry and its parameters will be used as an example, serving as a reference point for the other models. As a result of Joule heat generation, the system of linked busbars exceeded ambient temperature. Heat distribution on the surface of the busway is presented in Figure 3. Shown is an intense heating up on the edge of both contacts, stemming from the presence of a coating layer - copper oxide and increased current density. As the current in the enlarged cross-section flows through the shortest way (that is the centre), there is also a visible area of decreased temperature on external edges of the busbars. There is a noticeable disadvantageous disproportion in thermal distribution, causing more intensive heating up of particular elements of the busbars.

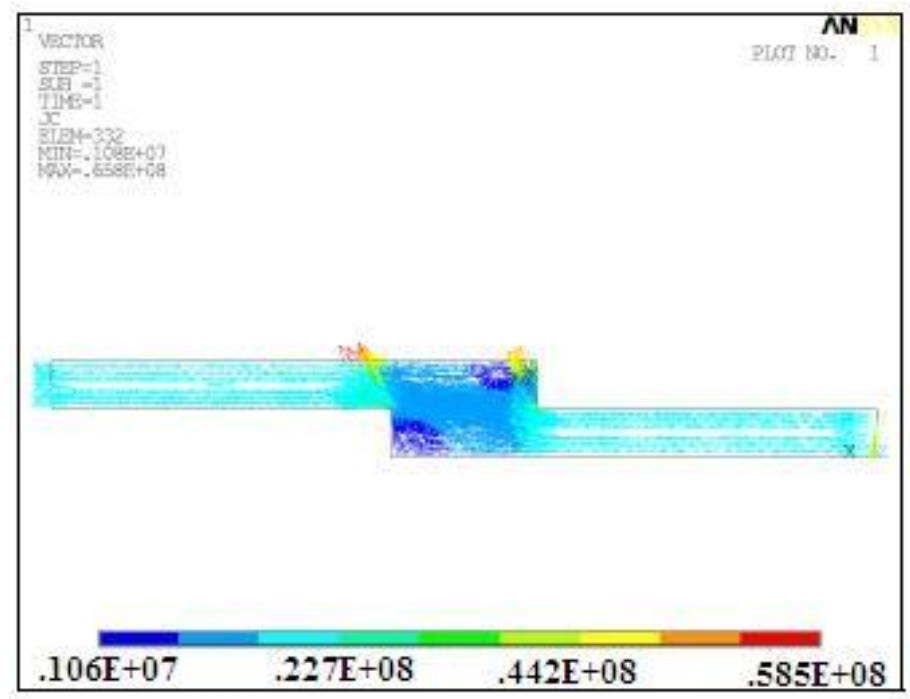

Fig. 2. Reference model, current density.

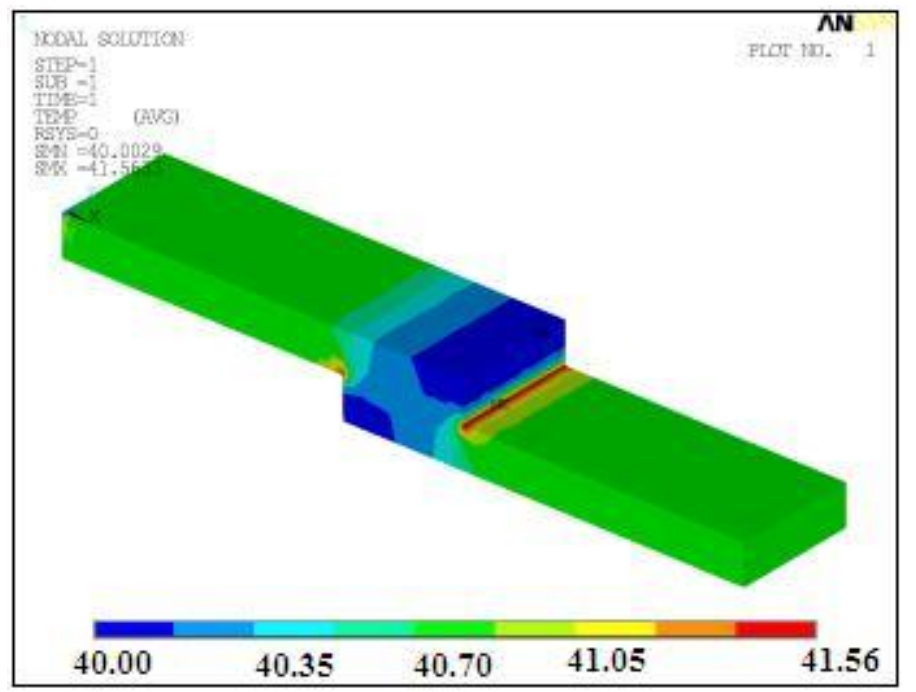

Fig. 3. Reference model, temperature distribution.

\section{EXTENDED BUS WIDTH}

It is a wider version of the reference busbar. Contact area is enlarged upon maintained length. With constant current value, greater conductive area contributes towards reduced heating up of the construction. Larger cross-section and enlarged conduction area positively influenced thermal conditions of the busbars link. This is related to decreased current density. Distribution of the current is remarkably more uniform as well. However, due to the costs involved this is not an optimal solution.

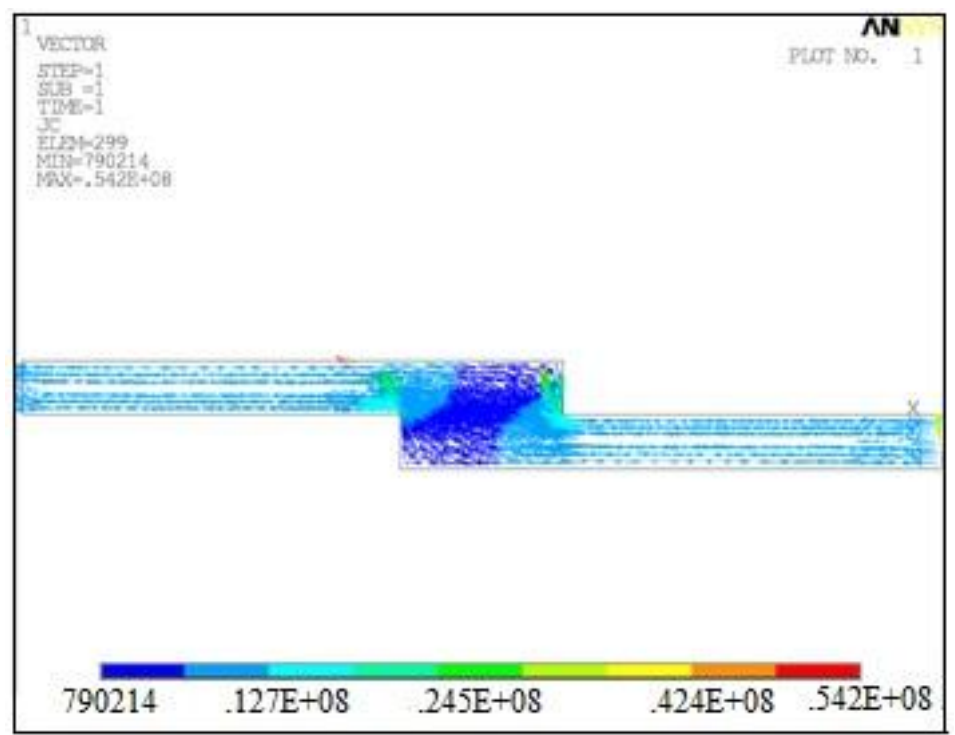

Fig. 4. Extended bus width, current density. 


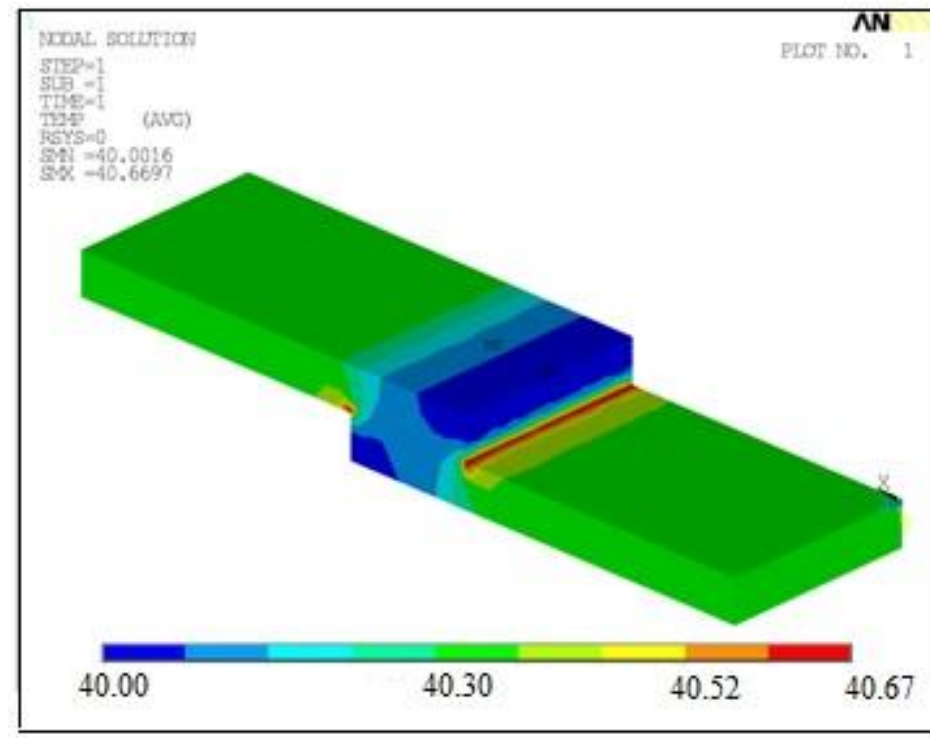

Fig. 5. Extended bus width, temperature distribution

\section{ALTERED PROPORTION OF CONTACT OVERLAP TO BUSBAR THICKNESS}

According to the theory, the larger the proportion of the length of contact overlap to the thickness of busbar, the lower the contact resistance value [6,7]. Given this, it should be noted that extending the length of contact overlap too much may cause an increase in transition resistance. A decrease of contact resistance is related to reduced heating up of the busbars. Such alteration of construction dimensions brings about positive results, seeing as reduced material use helps achieve better heat distribution and limit its generation.

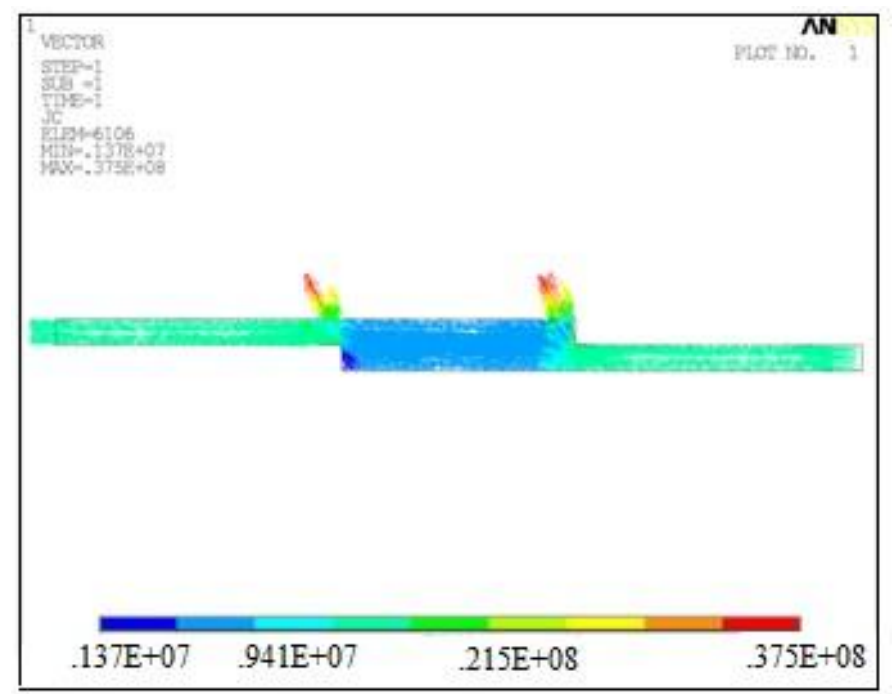

Fig. 6. Altered proportion of contact overlap to busbar thickness, current density.

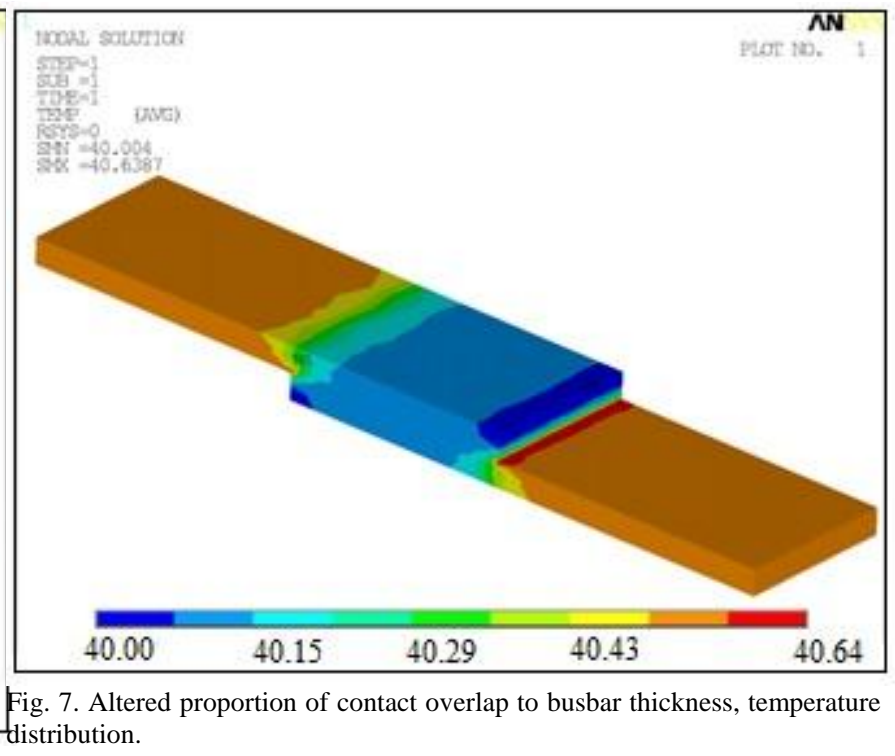

VI. CONSTRUCTION WITH BEVELLED EDGES

The model shows a construction which edges were cut at 45 degrees. This particular way of linking the busbars allows for a decrease contact resistance by as much as $15 \%$. The structure is also characterized by an extended heat transfer surface through convection, as well as reduced material usage. Any areas that did not participate in the flow of the current were removed, which contributed towards a more uniform heat distribution. Chamfering diminished power losses and improved operational conditions for the juncture. Figure 8., which presents the distribution of current density, shows how the flow conditions improved. Values from the whole corsssection were normalized.

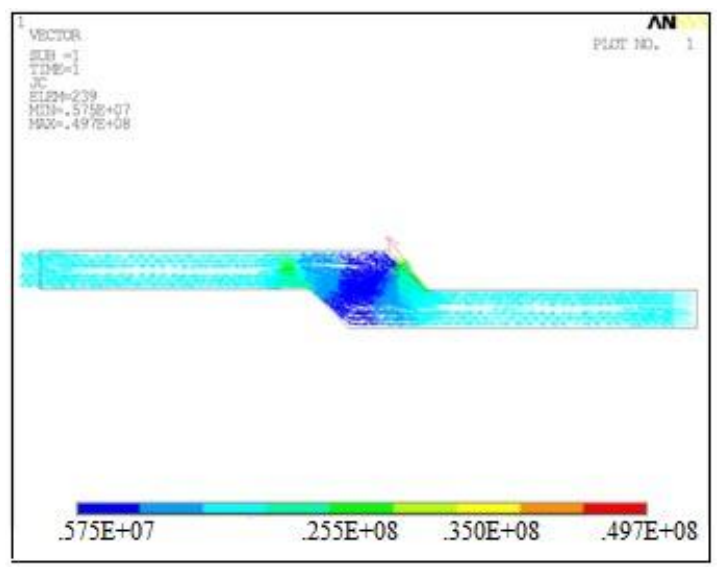

Fig. 8. Chamfered, current density. 


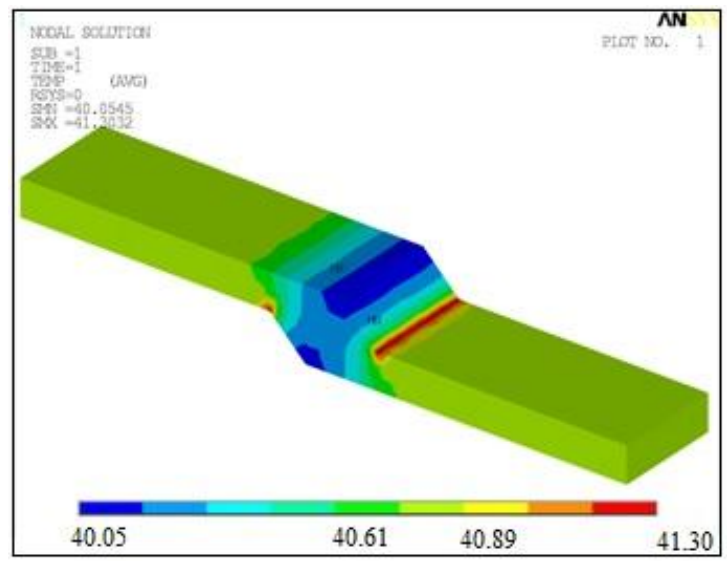

Fig. 9. Chamfered, current density.

\section{ENABLING ALL FEATURES IN ONE CONSTRUCTION}

Conclusions from each separate analysis were drawn as part of a summary, and as a result of this a busbar which combines all characteristics that improved thermal-electric conditions was modelled. In line with expectations, the model presents the lowest temperature and its most uniform distribution. This proves that the conclusions from conducted analyses were correct. Graphic representation of optimalization process and its correct result is presented on Figure 11. The life span of such construction is longer, since it's less exposed to local overheating of material.

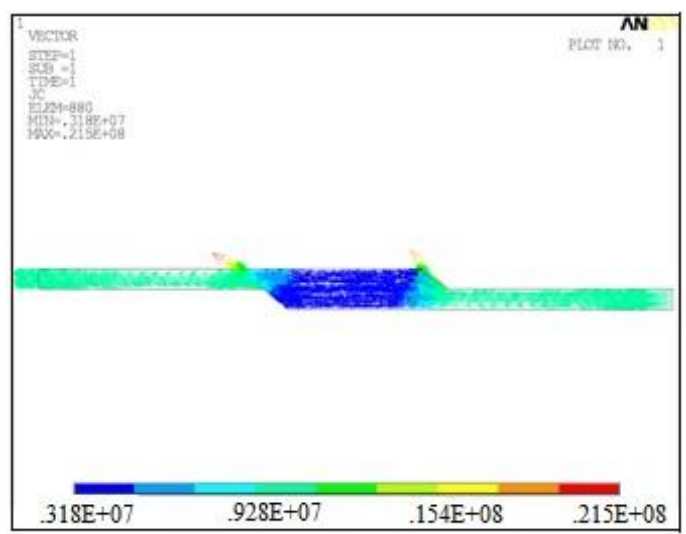

Fig. 10. Concluding model, current density.

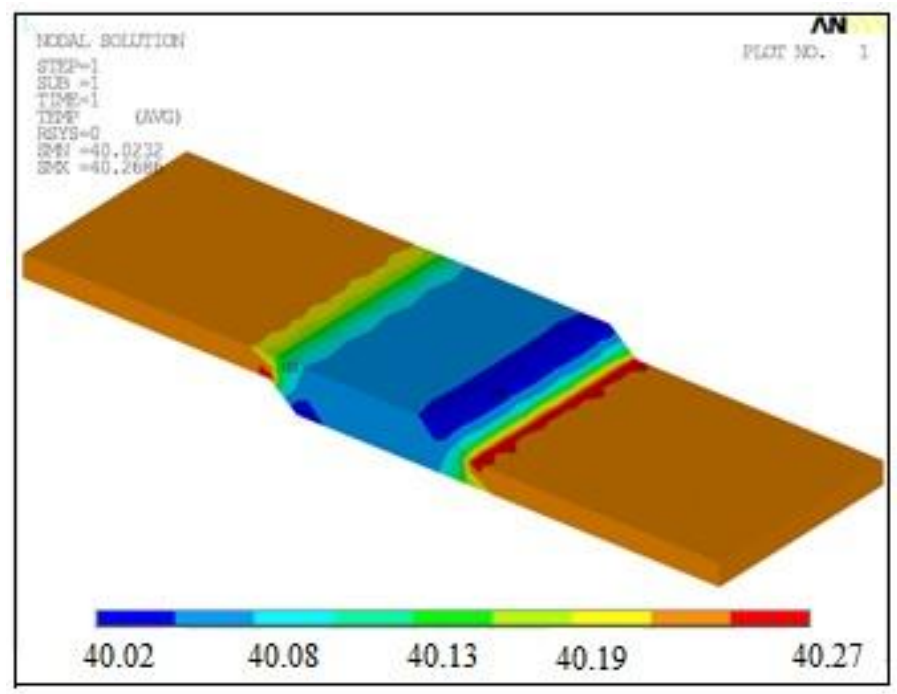

Fig. 11. Concluding model, temperature distribution.

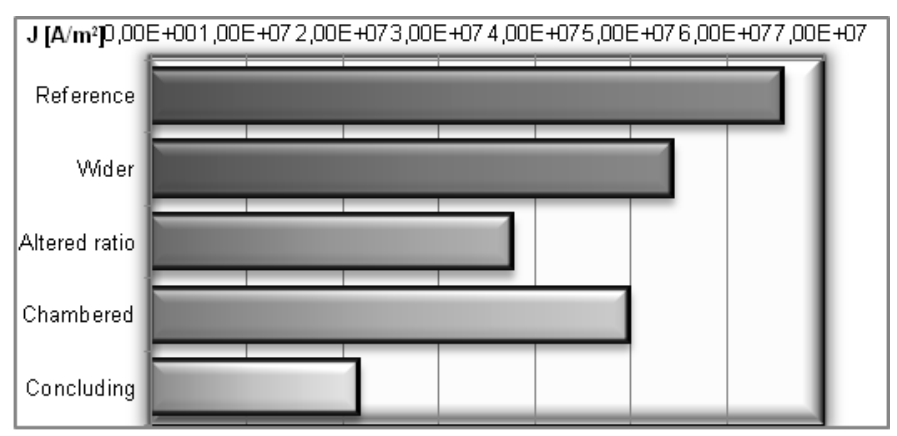

Fig. 12. Max. temperature comparison.

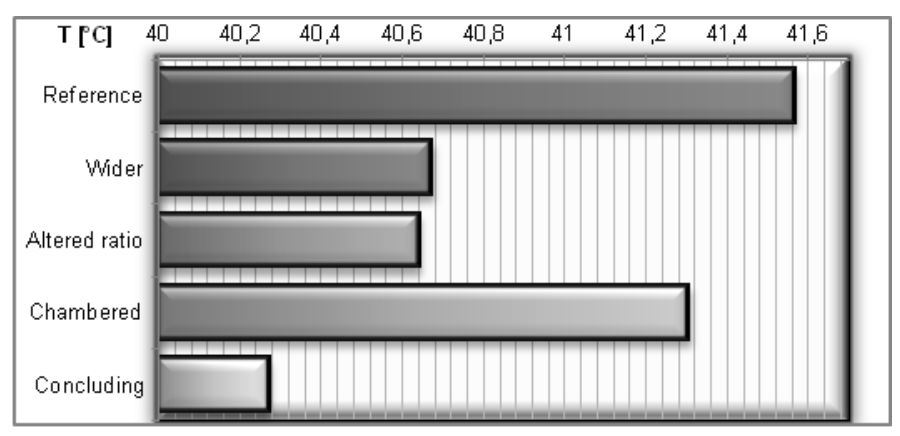

Fig. 13. Max. current density comparison.

\section{REFERENCES}

[1] Slade P.: „Electrical contact”, Manel Dekker inc., New York, 1999.

[2] Kuffel J., Zaengel W.: „Hight voltage engineering”, Bytter worth-Heinemann, Oxford, 2000.

[3] Kolimas Ł.: "The position and the procedure for checking the features of high voltage contact systems", ScieConf, pages 390-393.

[4] Copper for Busbars, CDA Publication 22, June 1996.

[5] Kolimas Ł..: „Modelling of Chosen Dynamic Behaviours of the Arc in Pin Arrangements", Conference of Informatics and Management Sciences, march 2013 , pages 349-351. 
[6] Kolimas Ł.: "Analysis of the Breakdown and Electrical Arc in the Process of Switching on", GSTF Journal of Engineering Technology (JET), Vol.2 No.2, 2013.

[7] Kolimas Ł., Kulas S.: "Optimization of Electric Field in Contacts on Example of Making Switch", Proceedings of the $42^{\text {th }}$ International Universities Power Engineering Conference, University of Brighton, Brighton, UK 2007, pp. 491-495.

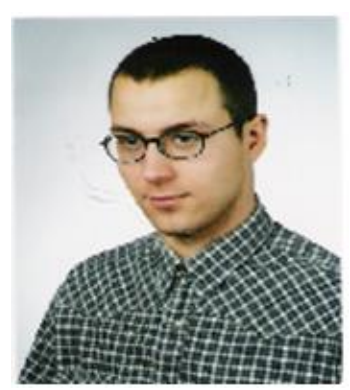

Lukasz Kolimas is a $\mathrm{PhD}$ Engineer, a Science officer in Warsaw University of Technology Decision of Power System Apparatus, Protection and Control. Personal economic activity related with professional technical counseling from 2007 to present. He was a PhD Student in Warsaw University of Technology, with a major in Electrical Engineering under the Electrical Apparatus Department from 2005-2006. He studied in Warsaw University of Technology (Power System and Robotics) and coordinated studios automation of drive form 2000-2005.

He practiced in PGNiG (Polish Oil and Gas Company) from june 2002 september 2002. He was a Conservator of elevator from june 2003 september 2003 and a counselor on OSRAM Company from 2006 - 2008 before being engaged in a Personal economic activity in 2008 . 